\title{
Article
}

\section{Electric Vehicle Fleets as Balancing Instrument in Micro-Grids}

\author{
Giambattista Gruosso *,+ ${ }^{(D)}$ and Fredy Orlando Ruiz ${ }^{+}$(D) \\ Dipartimento di Elettronica, Informazione e Bioingegneria-DEIB, Politecnico di Milano, Piazza Leonardo da \\ Vinci 32, 20133 Milano, Italy; fredy.ruiz@polimi.it \\ * Correspondence: giambattista.gruosso@polimi.it; Tel.: +39-02-2399-3696 \\ † These authors contributed equally to this work.
}

Citation: Gruosso, G.; Ruiz, F.O. Electric Vehicle Fleets as Balancing Instrument in Micro-Grids. Energies 2021, 14, 7616. https://doi.org/ $10.3390 /$ en14227616

Academic Editors: Maria Carmela Di Piazza and Javier Contreras

Received: 7 October 2021

Accepted: 11 November 2021

Published: 15 November 2021

Publisher's Note: MDPI stays neutral with regard to jurisdictional claims in published maps and institutional affiliations.

Copyright: (c) 2021 by the authors. Licensee MDPI, Basel, Switzerland. This article is an open access article distributed under the terms and conditions of the Creative Commons Attribution (CC BY) license (https:/ / creativecommons.org/licenses/by/ $4.0 /)$.

\begin{abstract}
Micro-grids have become the building block of modern energy systems, where distributed resources are the characterizing feature. The charging operation of electric vehicles can be exploited as a flexible load to achieve operational goals of the micro-grid. In the particular case of car-sharing fleets, the degrees of freedom in the charging procedures are reduced when compared to private users. In this work, we illustrate how a car sharing fleet can be incorporated as a flexible load in the micro-grid management system. A linear optimization problem is formulated, where the cost function makes a trade-off between the gain in flexibility in the micro-grid and the loss incurred by the car-sharing service for delaying the recharging procedure of the EV. The proposed approach is evaluated on a data set of charging events generated by a real car-sharing fleet showing that the EMS allows reducing the daily peak demand requested to the public grid and diminishes the operational costs.
\end{abstract}

Keywords: micro-grid planning; electrical vehicles; energy storage; flexible programming

\section{Introduction}

Today, nano and micro-grids play a strategic role in the development of the electricity system [1,2]. They represent, most of the time, autonomous energy communities [3], able to guarantee regulated energy exchanges, reducing the stress on the public distribution network. In these networks, it is possible to integrate different energy sources and at the same time new and programmable loads could be introduced. It becomes crucial to correctly plan energy flows in this context to optimize efficiency [4-7]. micro-grid architectures have different configurations, but in most cases the high use of renewable sources, such as solar, make these networks, on the one hand to behave with low inertia and on the other hand to count on generation resources, whose actual production is not easily predictable compared to the needs of the loads. It is, therefore, essential to have energy storage systems capable of promoting an optimal use of the resources. One of the most interesting and challenging solutions is to use Electric Vehicles (EV) as virtual storage systems [8-11]. Different optimization-based solutions to manage the charging profile of electric vehicles were proposed [12]. Most of the works assume that the electric vehicles are autonomous and an important effort is made in forecasting the arrival time of each EV and other uncertain variables, such as the arrival State of Charge $(\mathrm{SoC})[13,14]$, or in developing robust scheduling techniques that can guarantee an adequate power flow to/from the public grid, in front of any feasible realization of arrival time and SoC [15].

The existing solutions to manage the optimal charging of EV fleets have two main limitations. First, most of them need to track the dynamics of each vehicle in the fleet to accurately estimate its arrival time and $\mathrm{SoC}$. This approach poses a strong limitation on the scalability of the solution, as the complexity of the estimation and optimization problems grows linearly with the size of the fleet. In [12], a different approach is presented, where the main element of the model is the charging station and the arrival of EVs are handled as events that modify the state of the station. This configuration, limits the size of the 
problems to the number of stations handled by the management system. On the other hand, in the literature, the degrees of freedom that are considered to manipulate the charging profile of EVs are the power level and the charging interval, given some constraints on the total recharging time. However, none of the existing models takes into account the cost incurred by the fleet manager with a longer charging time. In the specific case of a car-sharing fleet, the operator of the sharing service actually suffers a loss when a EV is unavailable during the recharge event. The longer the charging time, the higher the loss.

In this paper, we present a method for planning a micro-grid operation in which renewable sources, electrical loads and a car-sharing fleet of EVs are present. The vehicles energy requests are extracted from a real use case of a car-sharing fleet. The proposed solution takes into account the operational policy of the car-sharing company to gain information about the structure of the problem, impose costs and constraints on the operation, and reduce uncertainty in the energy demand. An optimal control problem is formulated, considering that all the EVs are taken to recharge mode at the same state of charge level. Flexibility is added to the recharging process augmenting the interval available to achieve the target $\mathrm{SoC}$ status, at the cost of reducing the time available for the car-sharing service. A multi-objective cost function allows performing a trade-off between flexibility in the demand curve and effectiveness of the sharing service. The validity of the formulation is verified in different scenarios of load and renewable generation.

In Section 2, we present the problem setup including the description of the employed data bases of EV charging events, loads and local photo-voltaic generation. Section 3 describes the operation of the car-sharing service and the resulting constraints and costs for the micro-grid operation. Section 4 describes the proposed energy management system, the considered multi-objective optimization problem and constraints. Section 5 illustrates the characteristics of the solution through a numerical example. Finally, Section 6 gives some conclusions and future developments .

\section{Problem Setup}

The considered micro-grid is formed by an industrial and commercial site, constituted by two circuits, a photo-voltaic (PV) generation plant and a set of charging stations that serve a fleet of shared electric vehicles.The grid is modeled as a single bus with limited capacity to exchange power with the main grid as shown in Figure 1.

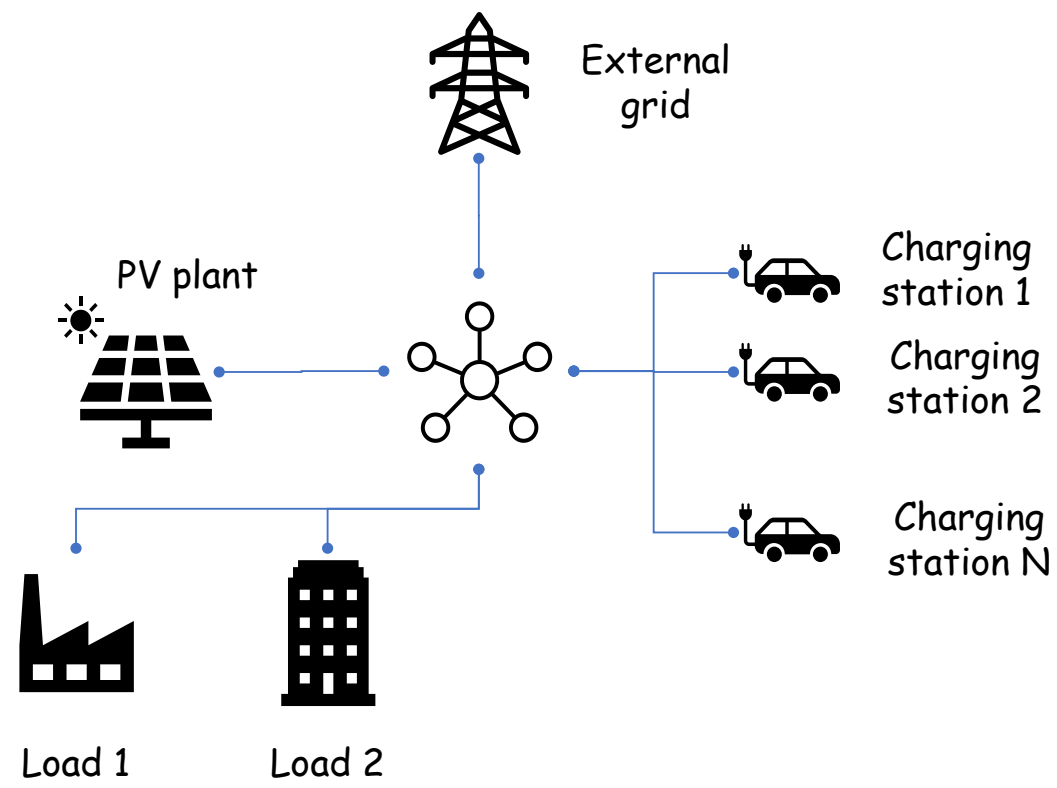

Figure 1. Micro-grid structure. 
The data used to model the behaviour of the EV fleet are those collected in the city of Milan in Italy during the Teinvein project [16]. This project monitored a fleet of electric vehicles used for car-sharing. The available data set contains recharging events performed in the around 200 public charging stations placed in the urban area.

By analyzing the behavior of the charging stations, it is possible to derive usage profiles that take into account the amount of energy withdrawn and the initial state of charge of the vehicles [17]. Using a fleet of vehicles, as opposed to individual owners data, allows for realistic estimations of virtual battery behavior. The fleet manager can plan how many cars to allocate to virtual storage and how many to make available to users. In addition, the fleet manager can define charging strategies. For example, in the considered case study, recharging occurs when the state of charge of the vehicles is around $20 \%$.

The arrival of the vehicles is asynchronous and can happen at very different moments. Moreover, each car can leave the location only when it has reached a predefined target $\mathrm{SoC}$ named $\overline{\mathrm{SoC}}$. Thus, the scheduling problem we set has to deal with challenging constraints to satisfy. Starting from the methodology proposed in [17] it is possible to obtain the occupation curves of the charging stations, such as for example those shown in Figure 2, where daily profiles of charging station occupation is shown for a set of 10 consecutive days. Each color represents a different day. It can be noticed that for this station the maximum occupation is 4 simultaneous EVs connected for recharging, and that several days present intervals without any EV connected to the station, thus limiting the flexibility of the micro-grid.

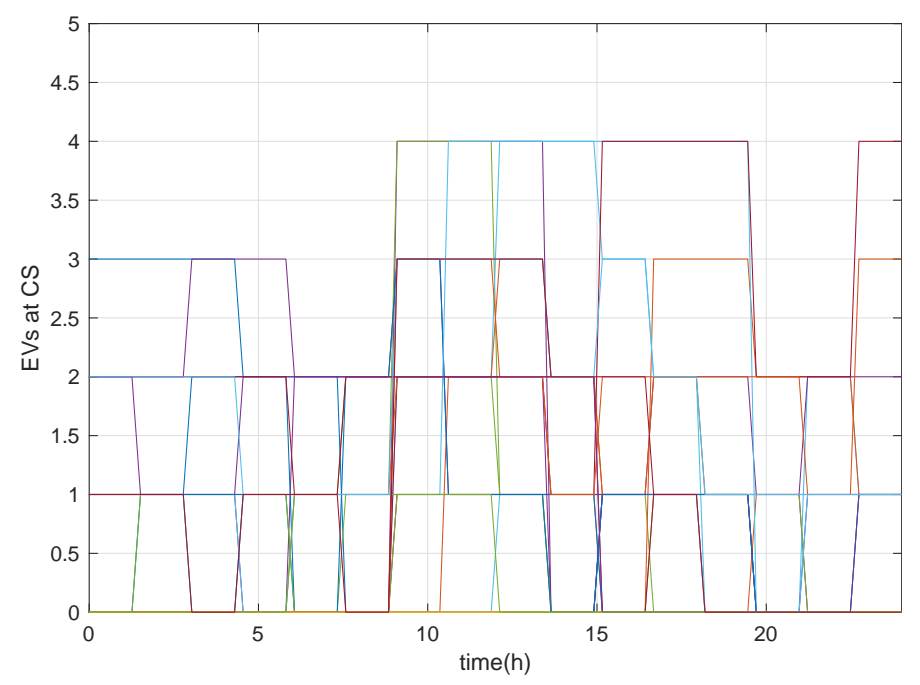

Figure 2. Sample of a Charging station occupation for one month.

As far as the modelling of loads and photo-voltaic sources is concerned, we rely on those presented in [18]. In that paper a multi-year database containing data from a real micro-grid is presented. The loads of the two circuits are assumed partially flexible and their typical behaviour is shown in Figure 3, where the daily profile of the load is illustrated for one year. Each color represents a different day. It can be noticed that the peak load occurs between the hours 10 and 18, also that the daily baseline can vary from $40 \mathrm{~kW}$ up to $70 \mathrm{~kW}$. 


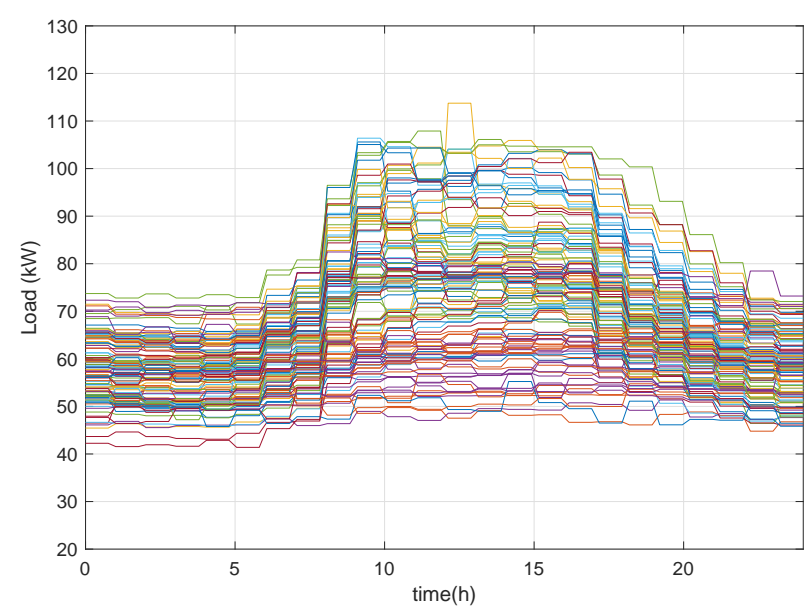

Figure 3. Sample of hourly demand profiles in the data set.

Similarly, photo-voltaic generation profiles are extracted form the data-base presented in [18]. In Figure 4, the daily generation profiles are reported for one year. Each color represents a different day. Please note that the daily peak production can rise up to $83 \mathrm{~kW}$.

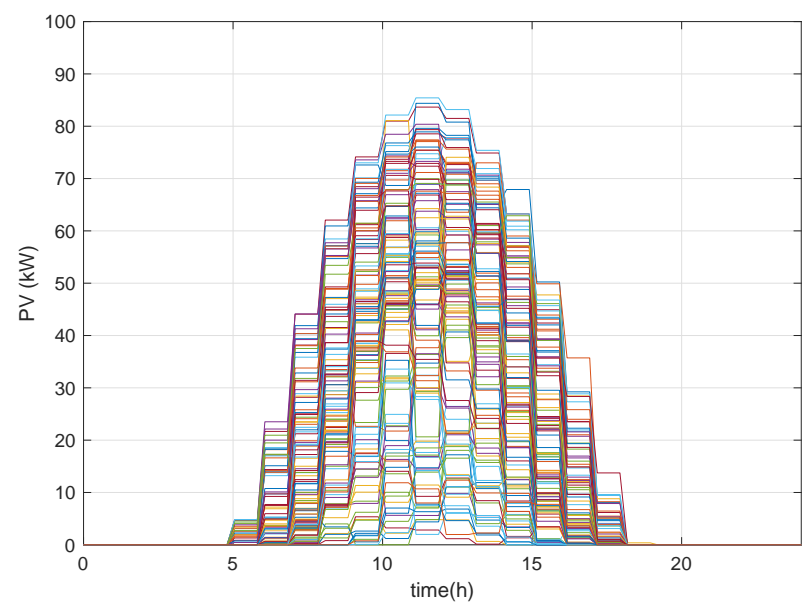

Figure 4. Sample of hourly PV plant generation profiles in the data set.

Table 1 shows the main parameters of the considered micro-grid.

Table 1. Microgird parameters.

\begin{tabular}{ccc}
\hline Element & Maximum Power $\mathbf{( k W )}$ & Average Power (kW) \\
\hline Load 1 & 120 & 68 \\
Load 2 & 120 & 84 \\
PV plant & 90 & 10 \\
External grid & 250 & N.D. \\
Charging station (each) & 3 & N.D. \\
\hline
\end{tabular}

Finally, the cost of the energy acquired from the public grid, considered in the case study, is a standard time-of-use rate with three different price ranges:

- $\quad$ early morning/late evening

- mid-day

- peak-hours 


\section{Management System}

The energy management systems is the gateway between the controllers of the main elements of the micro-grid and the public grid. It uses the forecasts on the arrival time of vehicles, and the trend of loads and renewable sources to make optimal decisions about flexible loads activation and EV charging profiles. The architecture is shown in Figure 5. Here, the lines represent information flows and the arrows their direction. That means that the EMS obtains information from the forecasts providers about generation, EV charging events, load profiles and energy tariffs, but without affecting their decisions. On the other hand, the EMS interacts with flexible loads and charging stations in a two-way communication. In one direction it obtains information about the real-time status of the consumption, charging station status, connected EVs, etc., and, on the other, it commands how to activate flexible loads and how to modify the charging profile of each EV connected to the station.

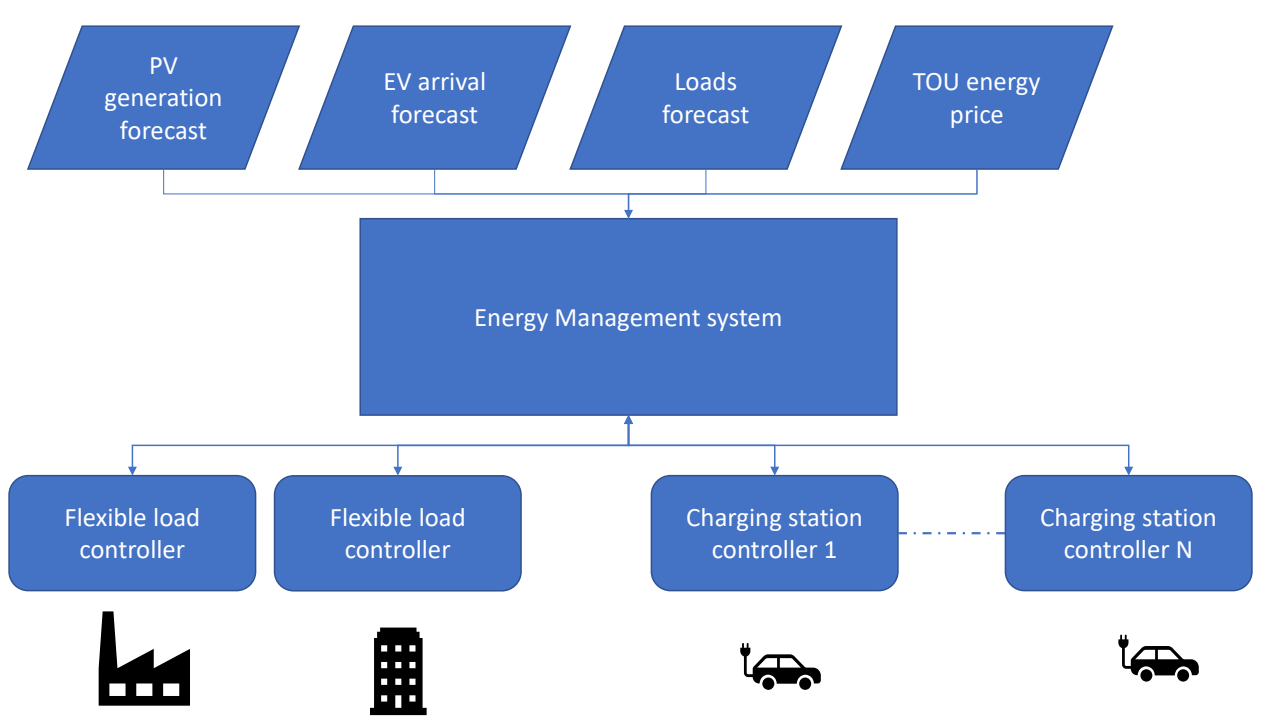

Figure 5. Structure of the Energy Management System.

The management system works to make sure that the power balance of the micro-grid is satisfied at each instant, while optimizing a set of Key Performance Indicators.

The power balance of the system is:

$$
P_{\text {grid }}(t)+P_{P V}(t)=P_{L 1}(t)+P_{L 2}(t)+\sum_{i=1}^{N} P_{i}^{C S}(t)
$$

where $P_{\text {grid }}(t)$ is the power absorbed to the main grid, $P_{P V}(t)$ is the power generated by the photo-voltaic plant, $=P_{L i}(t)$ is the power consumed by each circuit load, and $P_{i}^{C S}(t)$ is the power consumed by each charging station.

Please note that if the loads are inflexible and the charging stations operate without any management system, recharging each EV at maximum power from its arrival until achieving the target $\mathrm{SoC}$ condition, the power balance can only be guaranteed by modifying the power absorbed to the main grid.

The aim of the energy management system is to offer a feasible power flow while maintaining each component within its technical limits, exploit the flexibility of the EVs charging process and of the loads, to optimize the operational cost of the grid and minimizing the power exchanges with the main grid.

To provide some flexibility to the micro-grid, in the literature it was proposed to install local energy resources, such as traditional generators and/or static storage systems. However, if none of these resources are available, adding a management system to the 
charging stations can allow the micro-grid to achieve the proposed objectives at the expense of increasing the charging time of the electric vehicles.

\section{EV Fleet Recharging Policy}

As shown in [17], in the present framework we are dealing wit a set of uniform vehicles with the same decision criteria, all the EVs are taken to the charging station when the $\mathrm{SoC}$ achieves a prescribed level and all of them are given the same time window to come back to operation. The aim of this section is to formulate a formal description of the recharging policy, to be employed later in the optimization problem solved by the EMS.

As described at the beginning of Section 2, the operation policy of the charging station entails the continuous supervision of the $\mathrm{SoC}$ of each vehicle and the decision to recharge the vehicle whenever its state goes below a prescribed level. Let $\sigma_{i}(t)$ be a binary variable representing the operation mode of vehicle $i$, where $\sigma_{i}(t)=0$ means that vehicle $i$ is operating in car-sharing mode during the time interval $t$ and $\sigma_{i}(t)=1$ means that at period $t$ the vehicle is in recharging mode.

The policy can be summarized as follows:

1. While an EV is in car sharing service, supervise its $S o C$ and

$$
\text { if } \operatorname{SoC}_{i}(t) \geq \underline{\text { SoC }} \text { and } \sigma_{i}(t)=0 \Rightarrow \sigma_{i}(t+1)=0 ;
$$

2. When the $S o C$ of the EV drops below $\underline{S o C}$ end the car-sharing operation and bring it to the charging station.

$$
\text { if } \operatorname{SoC}_{i}(t)<\underline{\text { SoC }} \text { and } \sigma_{i}(t)=0 \Rightarrow \sigma_{i}(t+1)=1 \text { and } t_{a i}=t \text {. }
$$

3. At the beginning of the charging process set the target departure time from the charging station as

$$
t_{d i}=t_{a i}+\Delta_{T}
$$

where $\Delta_{T}$ is the maximum allowed recharging time.

4. At the charging station, supervise the recharging procedure and bring back the EV to service as soon as the $S o C$ rises above $\overline{S o C}$ :

$$
\text { if } \operatorname{SoC}_{i}(t) \geq \overline{\operatorname{SoC}} \text { and } \sigma_{i}(t)=1 \Rightarrow \sigma_{i}(t+1)=0 .
$$

Introducing $X_{i}(t)$ as the state variable representing the state of charge of charging station $i$, the previous recharging policy leads to the following dynamics from the point of view of the charging station:

$$
X_{i}(t+1)= \begin{cases}0 & \text { if } \sigma_{i}(t)=0 \\ S o C_{o} & \text { if } \sigma_{i}(t)=1 \text { and } \sigma_{i}(t-1)=0 \\ X_{i}(t)+\delta_{t} \eta \sigma_{i}(t) P_{i}^{C S}(t) & \text { if } \sigma_{i}(t)=1 \text { and } \sigma_{i}(t-1)=1\end{cases}
$$

Please note that the previous formulation decouples the usage of each EV and the recharging process.

\section{Flexibility-Based Energy Management System}

In this section, we describe the proposed a novel EMS that relies on the particular recharging policy of the EV fleet.

The EMS is based on an multi-objective optimization problem with uncertain constraints. 
The micro-grid incurs in different costs during normal operation. The main cost is the provision of energy from the main grid. Considering a Time of Use (ToU) tariff the grid energy cost for a given time interval is:

$$
J_{\text {grid }}=\sum_{k=0}^{T_{H}} \pi_{\text {grid }}(t+k) P_{\text {grid }}(t+k) \delta_{t}
$$

where $\pi_{\text {grid }}(t)$ is the cost per $\mathrm{kWh}$ of energy bought to the main grid.

At each charging station, there is a cost associated with the time elapsed for the charging process of each vehicle. It is defined as an increasing function of the recharging interval whenever the process takes longer than the minimum feasible charging time, that is,

$$
J_{C S i}=\sum_{k=0}^{T_{H}} \operatorname{step}\left(k-\Delta_{C}\right)\lfloor\overline{S o C}-S o C(t+k)\rfloor
$$

where $\Delta_{C}$ is the shortest interval required to achieve the target $S o C$ when the charging station applies the maximum acceptable power to the EV. Figure 6 illustrates the time evolution of the cost $J_{C S i}$.

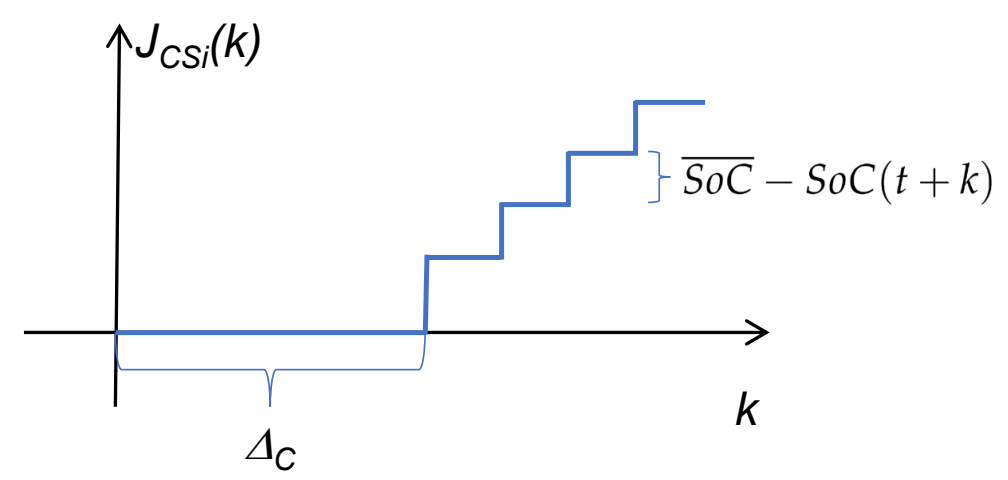

Figure 6. Time evolution of the cost associated with the delayed charging process.

For each circuit of the micro-grid, it is assumed that there is a set of referable loads that can provide flexibility to the operation. The activation of these loads has a cost related to the discomfort caused to the users of the services plus the operational cost of the demand management systems. The capacity of the flexibility service is limited to $10 \%$ of the forecast power at each interval, while the daily consumption must keep constant. The costs related to the flexible loads can be expressed as:

$$
J_{F L i}=\sum_{k=0}^{T_{H}} \pi_{F L} \delta_{t}\left\lfloor\widehat{P}_{L i}(t)-P_{L i}(t)\right\rfloor
$$

where $\pi_{F L}$ is the reduction cost per $k W h$ and $\widehat{P}_{L i}(t)$ is the forecast consumption at time $t$.

Finally, The effective consumption at time $t$ is constraint as:

$$
0.9 \widehat{P}_{L i}(t) \leq P_{L i}(t) \leq 1.1 \widehat{P}_{L i}(t)
$$

and the daily consumption as:

$$
\sum_{t=0}^{T_{\text {end }}} \widehat{P}_{L i}(t)=\sum_{t=0}^{T_{\text {end }}} P_{L i}(t) .
$$

The problem of the EMS is to minimize the different costs related to the micro-grid operation, manipulating the power applied to the EVs during the recharge interval and activating flexible loads when necessary. 
For a receding horizon of length $N$, the problem faced by the EMS can be stated as:

$$
\min _{\left(P_{i}^{C S}(k), P_{L i}(k)\right), k=t, t+1, \ldots, t+T_{H}} J_{g r i d}+J_{F L 1}+J_{F L 2}+\sum_{i=1}^{N} J_{C S i}
$$

Subject to

$$
P_{\text {grid }}(k)=\widehat{P}_{L 1}(k)+\widehat{P}_{L 2}(k)+\sum_{i=1}^{N} P_{i}^{C S}(k)-\widehat{P}_{P V}(k) ; k=\left(t, t+1, \ldots, T_{H}\right)
$$

Car-sharing policy and charging station dynamics, Equations (2)-(6)

Flexible loads constraints, Equations (10) and (11)

where $\widehat{P}_{L 1}(k)$ and $\widehat{P}_{L 2}(k)$ are the estimates of the load power for interval $k$ and $\widehat{P}_{P V}$ is the PV power generation estimate at time $k$.

Please note that to solve problem (12), the EMS must have access, as well as to the forecast of load and PV generation, also to the arrival and departure information of the EVs for each charging station, i.e., signals $\sigma(t)$ and $S_{o} C_{0}$. These signals are not know a priori, but the recharging policy of the fleet and historical data of the fleet operation allows building adequate estimators. For example, the arrival SoC of each vehicle is assumed to be $\underline{S o C}$, as this is the threshold to start a charging event. About the arrival time, each time the optimization algorithm is executed, an average number of charging events is estimated for the prediction horizon $T_{H}$, based on the data base of charging events. In this form, the optimal management of the currently connected vehicles is obtained for the most likely scenario. Then, at the next sampling time, the actual number of connected vehicles, the power forecasts and the expected EV arrivals are updated, generating a new power management policy in a receding horizon setup.

About the complexity of problem (12), it is a linear program, whose dimensionality depends on the number of flexible loads circuits and charging stations, but not on the size of the EV fleet. It can be noticed that all the terms in the cost function depend linearly on the decision variables, the power balance is a linear constraint, flexible loads capacity and daily limits are also linear constraints, while the car-sharing policy and charging station dynamics involve also linear equality and inequality constraints. Please note that from the point of view of the optimizer, the status of each charging station $\sigma_{i}(t)$ is a known binary signal, not a decision variable. These characteristics make the algorithm efficient ant scalable.

\section{Numerical Results}

The EMS proposed in the previous section was evaluated on a 235 days long simulation. The load and PV generation data are extracted from the data base reported in [18]. The EV fleet recharging events are taken from the data base reported in [17].

The sampling time of the EMS, $\delta_{t}$ is selected as $0.25 \mathrm{~h}$. This interval is fast enough to update the scheduling whenever a EV is connected to a charging station. The minimum recharging interval $\Delta_{C}$ is set as 4 hours, that is the period required to fully charge the vehicle using the highest power level, without any flexibility consideration. The prediction horizon $T_{H}$ is fixed as $8 \mathrm{~h}$. This length allows planning the complete recharging process of all the EVs connected to the CSs at a given sampling instant.

Figure 7 shows a box-plot of the peak power requested to the grid. It can be seen that the proposed EMS reduces both the worst-case power request to the grid and the mean of the peak power along the 235 days. The worst-case peak power is reduced from $123 \mathrm{~kW}$ to $112 \mathrm{~kW}$ and the median from $105 \mathrm{~kW}$ to $99 \mathrm{~kW}$. this effect can alleviate congestion events in the grid. Figure 8 shows a histogram of the daily energy cost of the micro-grid. For each price bin, the vertical axis reports the percentage of the 235 simulated days that has a cost within the bin interval. It is observed that the operational costs are reduced by $3 \%$ in this simulation. Finally, Figure 9 shows a sample of the daily load profile of 
the micro-grid. Please note that the EMS reduces the peak and generates longer charging intervals. This modification can cause a loss to the fleet operator. However, the savings in energy provision can compensate the longer recharging times.

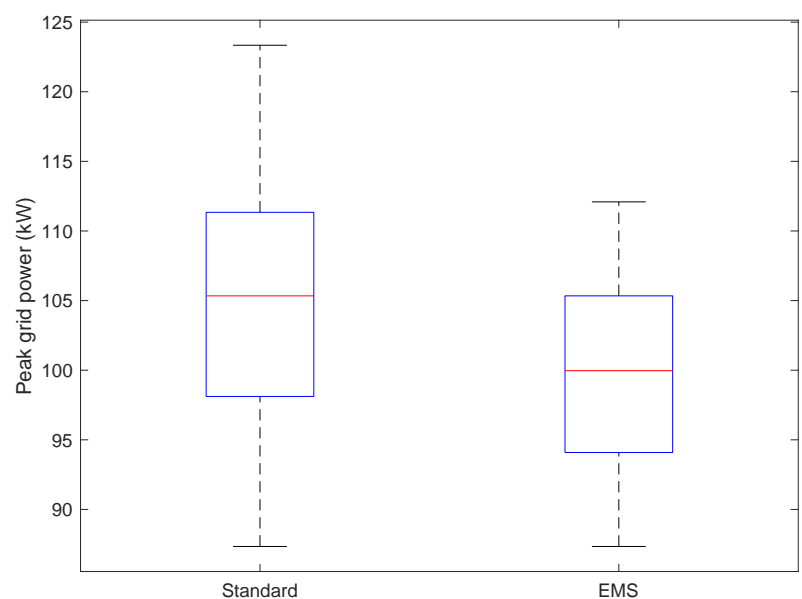

Figure 7. Boxplot of peak power requested to the main grid under standard (left) and optimal (right) EMS for the EV fleet.

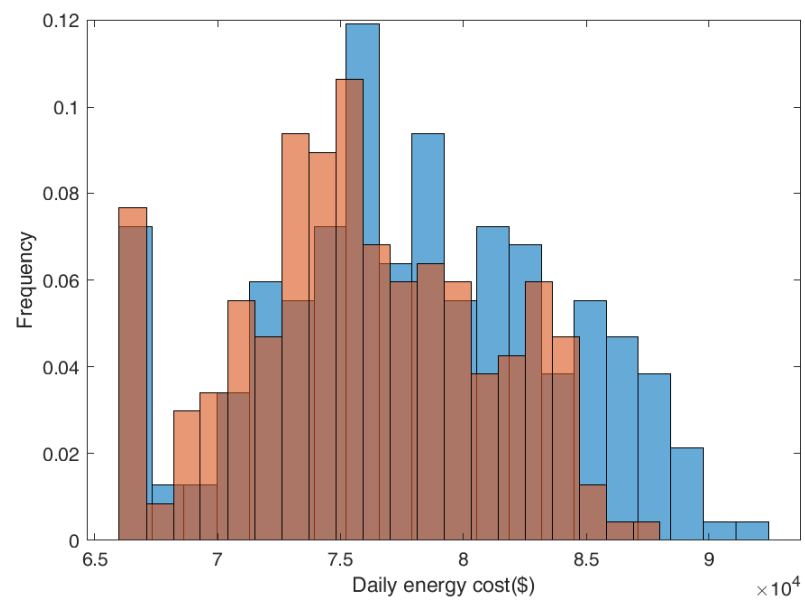

Figure 8. Histogram of daily energy cost of the micro-grid under standard (blue) and optimal (orange) EMS for the EV fleet.

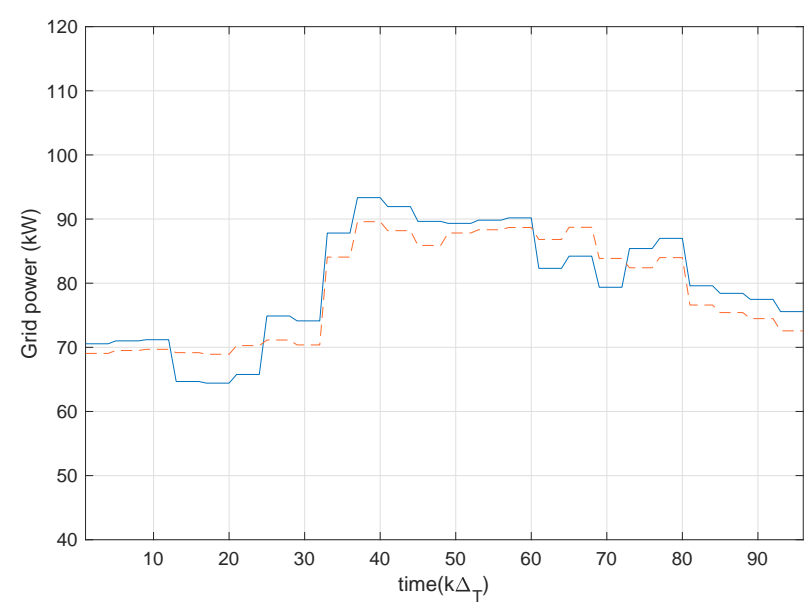

Figure 9. Sample daily profile of power requested to the main grid under standard (blue) and optima (orange) EMS for the EV fleet. 


\section{Conclusions}

In this work, we proposed an energy management system for a micro-grid that exploits the particularities of an EV fleet used in a car-sharing service. The system schedules the charging power of each vehicle considering the energy cost and forecast information about load and renewable generation. The cost function allows making a trade-off between flexibility exploitation to reduce energy costs and the lost in the car-sharing service caused by a longer recharging time. The methodology is evaluated through a long simulation campaign, considering experimental data of load profiles, PV generation and EV charging events from a car-sharing fleet. The results show that the EMS is able to reduce the peak power consumption of the micro-grid, extending the charging time from 4 to 5 or $6 \mathrm{~h}$. Further investigation is required to evaluate the sensitivity of the solution to uncertainty in the forecast information about fleet behavior, load and PV generation.

Author Contributions: Conceptualization, G.G. and F.O.R.; methodology, G.G. and F.O.R.; software, F.O.R.; validation, G.G. and F.O.R.; data curation, G.G. and F.O.R.; writing-original draft preparation, G.G. and F.O.R.; writing-review and editing, G.G. and F.O.R. All authors have read and agreed to the published version of the manuscript.

Funding: This research received no external funding.

Institutional Review Board Statement: Not applicable.

Data Availability Statement: No data are available.

Conflicts of Interest: The authors declare no conflict of interest.

\section{References}

1. Moreno-Munoz, A. Special Issue "Nanogrids, Microgrids, and the Internet of Things (IoT): Towards the Digital Energy Network". Energies 2019, 12, 3878. [CrossRef]

2. Gandhi, K.; Gupta, S. Operational strategies and electricity market structure of Microgrid: A Critical Review. Renew. Energy Focus 2021, 39, 163-171. [CrossRef]

3. Perez-DeLaMora, D.; Quiroz-Ibarra, J.E.; Fernandez-Anaya, G.; Hernandez-Martinez, E. Roadmap on community-based microgrids deployment: An extensive review. Energy Rep. 2021, 7, 2883-2898. [CrossRef]

4. Bagheri Tookanlou, M.; Marzband, M.; Al Sumaiti, A.; Mazza, A. Cost-benefit analysis for multiple agents considering an electric vehicle charging/discharging strategy and grid integration. In Proceedings of the 2020 IEEE 20th Mediterranean Electrotechnical Conference (MELECON), Palermo, Italy, 16-18 June 2020; pp. 19-24. [CrossRef]

5. Al-Ismail, F.S. DC Microgrid Planning, Operation, and Control: A Comprehensive Review. IEEE Access 2021, 9, $36154-36172$. [CrossRef]

6. Rafiee Sandgani, M.; Sirouspour, S. Energy Management in a Network of Grid-Connected Microgrids/Nanogrids Using Compromise Programming. IEEE Trans. Smart Grid 2018, 9, 2180-2191. [CrossRef]

7. Lee, S.; Jin, H.; Vecchietti, L.F.; Hong, J.; Har, D. Short-Term Predictive Power Management of PV-Powered Nanogrids. IEEE Access 2020, 8, 147839-147857. [CrossRef]

8. Dang, Q.; Wu, D.; Boulet, B. EV Fleet as Virtual Battery Resource for Community Microgrid Energy Storage Planning Le parc de véhicules électriques comme ressource de batterie virtuelle pour la planification du stockage d'énergie des micro-réseaux communautaires. IEEE Can. J. Electr. Comput. Eng. 2021, 1-12. [CrossRef]

9. Vuelvas, J.; Ruiz, F.; Gruosso, G. A time-of-use pricing strategy for managing electric vehicle clusters. Sustain. Energy Grids Netw. 2021, 25, 100411. [CrossRef]

10. Dinkhah, S.; Negri, C.A.; He, M.; Bayne, S.B. V2G for Reliable Microgrid Operations: Voltage/Frequency Regulation with Virtual Inertia Emulation. In Proceedings of the 2019 IEEE Transportation Electrification Conference and Expo (ITEC), Detroit, MI, USA, 19-21 June 2019; pp. 1-6. [CrossRef]

11. Vuelvas, J.; Ruiz, F.; Gruosso, G. Energy price forecasting for optimal managing of electric vehicle fleet. IET Electr. Syst. Transp. 2020, 10, 401-408. [CrossRef]

12. Diaz-Londono, C.; Colangelo, L.; Ruiz, F.; Patino, D.; Novara, C.; Chicco, G. Optimal Strategy to Exploit the Flexibility of an Electric Vehicle Charging Station. Energies 2019, 12, 3834. [CrossRef]

13. Diaz-Londono, C.; Ruiz, F.; Mazza, A.; Chicco, G. Optimal Operation Strategy for Electric Vehicles Charging Stations with Renewable Energy Integration. IFAC-PapersOnLine 2020, 53, 12739-12744. [CrossRef]

14. Giordano, F.; Arrigo, F.; Diaz-Londono, C.; Spertino, F.; Ruiz, F. Forecast-Based V2G Aggregation Model for Day-Ahead and Real-Time Operations. In Proceedings of the 2020 IEEE Power Energy Society Innovative Smart Grid Technologies Conference (ISGT), Washington, DC, USA, 17-20 February2020; pp. 1-5. [CrossRef] 
15. Badami, M.; Fambri, G.; Mancò, S.; Martino, M.; Damousis, I.G.; Agtzidis, D.; Tzovaras, D. A Decision Support System Tool to Manage the Flexibility in Renewable Energy-Based Power Systems. Energies 2020, 13, 153. [CrossRef]

16. Gajani, G.; Bascetta, L.; Gruosso, G. Data-driven approach to model electrical vehicle charging profile for simulation of grid integration scenarios. IET Electr. Syst. Transp. 2019, 9, 168-175. [CrossRef]

17. Gruosso, G.; Mion, A.; Storti Gajani, G. Forecasting of electrical vehicle impact on infrastructure: Markov chains model of charging stations occupation. eTransportation 2020, 6, 100083. [CrossRef]

18. Vink, K.; Ankyu, E.; Koyama, M. Multiyear microgrid data from a research building in Tsukuba, Japan. Sci. Data 2019, 6, 190020. [CrossRef] [PubMed] 